\title{
Lipid Metabolism in the Cattle in Different Stages of Reproductive Cycle
}

\author{
Mihok Tomáš, Bujňák Lukáš, Hreško Šamudovská Alena, Maskal’ová Iveta and Zigo František* \\ Department of Nutrition and Animal Husbandry, University of Veterinary Medicine and Pharmacy \\ Košice, Slovakia \\ *Corresponding author's mail: frantisek.zigo [AT] uvlf.sk
}

\begin{abstract}
The aim of this study was to evaluate the effect of feeding dairy cows in different stages of reproductive cycle on biochemical parameters and oxidative stress. To evaluate the effect of oxidative stress on lipids and lipid metabolism and to determine impact of nutrition and energy balance on oxidative stress in peripartum period and in early lactation. Concentrations of different biochemical parameters were measured but for this paper the most important ones were indicators of oxidative stress, cholesterol and triglycerides and also albumin. Factors associated with oxidative stress were period 3 weeks before calving and related to that negative energy balance and also content of nonfiber carbohydrates in the diet in peripartum period. However, further studies will be needed to more precisely determine the specific effects of diet and energy balance on oxidative stress in cows and to establish normal ranges for these biomarkers of oxidative stress.
\end{abstract}

Keywords - Cow, Peripartum period, Lipid metabolism, Oxidative stress

\section{[1] INTRODUCTION}

Oxidative stress (OS) occurs when prooxidants exceed the antioxidant capacity [1]. This predominance can occur due to excessive production or supply of pro-oxidative factors (or their local accumulation), or failure of antioxidant mechanisms. The long-term effect of oxidative stress can result in damage to biologically important molecules and structures and subsequent death of the cell or organism [2]. Oxidative stress is involved in many disease processes in cows, including sepsis, mastitis, enteritis, pneumonia, respiratory and joint diseases [3].

Prooxidation factors include all molecules that are able to cause oxidation of other substances. These are mainly radicals - molecules that contain unpaired electrons and also molecules that are able to produce radicals or, by their effect, help produce radicals. Radicals were one of the first known prooxidation factors. However, it is now known that in addition to radicals, there are many other molecules which exhibit prooxidant properties, so the name reactive forms is currently preferred. We divide these according to the most important atom in them into reactive forms derived from oxygen (ROS), nitrogen and others. They can come from exogenous sources, most of them are endogenous [2].

Oxygen-derived reactive forms form the largest and most important group. These include molecules of the radical type (hydroxyl radical HO-, superoxide anion $\mathrm{O} 2$-) and non-radical type (hydrogen peroxide $\mathrm{H}_{2} \mathrm{O}_{2}$, organic peroxides) [2]. An imbalance between ROS production and safe disposal can initiate oxidative chain reactions and lipid peroxidation [1]. In addition to oxygen-derived reactive forms, an excessive amount of nitrogen-derived reactive forms can be formed in the body under oxidative stress. Nitric oxide is also a radical molecule. NO has the ability to react very rapidly with reactive oxygen molecules (especially superoxide anion) and, depending on the environment, other reactive nitrogen molecules such as nitrosonium cation $\mathrm{NO}+$, nitronium cation $\mathrm{NO} 2+$, nitroxyl anion $\mathrm{NO} 2-$ or peroxonitrite anion . ONOO- may be formed, which may further transform to nitrogen dioxide NO2 and hydroxyl radical HO- These are able to trigger other radical reactions that can lead to damage to biologically active molecules [4].

Antioxidant factors counterbalance the prooxidant factor and protect the body from oxidative stress. We divide them into: a) antioxidants that prevent the formation of free radicals, free radical scavengers that remove already formed free radicals b) repair enzymes that scavenge and repair already damaged molecules [2]. If free radicals are not effectively and safely eliminated, oxidative stress can directly or indirectly impair cow health [1]. Free radicals can impair cell function because they can damage cell lipids, proteins, and DNA $[1 ; 5]$.

Lipids are one of the most sensitive substrates to free radical damage and biomarkers of lipid peroxidation are considered to be the best indicators of oxidative stress [6]. Malondialdehyde (MDA) is one of the few low molecular weight end products that is formed during the radical-induced decomposition of polyunsaturated fatty acids [7]. MDA reacts easily with thiobarbituric acid to produce a red pigment that can be easily measured with a spectrophotometer in the form of thiobarbituric acid reactive substances (TBARS) [7]. 


\section{[2] MATERIAL AND METHODOLOGY}

\subsection{Dairy herd and sampling}

All the animals were under regular veterinary supervision by the veterinarian at the farm for the duration of the entire experiment. Animal care was carried out in compliance with Directive 2010/63/EU of the European Parliament and of the Council of 22. September 2010 on the Protection of Animals Used for Scientific Purposes [8]. The experiment was carried out at Cattle Farm in Zemplínska Teplica in Slovakia. Twelve cows were used in the experiment, divided evenly into two groups - dairy cows three weeks before calving and dairy cows in the first stage of lactation. The nutritional value of the total mixed ration (TMR) was analyzed at the Department of Animal Nutrition and Husbandry in Košice (Tables 1, 2 and 3). To determine the individual biochemical parameters, we drew blood from the jugular vein and examined the mentioned biochemical parameters with an automatic Ellipse analyzer. In our work, we paid attention to the following parameters: oxidative stress, cholesterol, triglycerides and albumin.

Table 1: Composition of total mixed ration (3 weeks before calving)

\begin{tabular}{cc}
\hline & 3 weeks before calving \\
\hline Corn silage & $15 \mathrm{~kg}$ \\
Oat silage & $4 \mathrm{~kg}$ \\
Meadow hay & $2.5 \mathrm{~kg}$ \\
Wheat straw & $1 \mathrm{~kg}$ \\
Rapeseed meal & $1 \mathrm{~kg}$ \\
Cereal grain mixture & $3 \mathrm{~kg}$ \\
\hline
\end{tabular}

Table 2: Composition of total mixed ration ( $1^{\text {st }}$ stage of the lactation)

\begin{tabular}{cc}
\hline & $\mathbf{1}^{\text {st }}$ stage of the lactation \\
\hline Corn silage & $30 \mathrm{~kg}$ \\
Alfalfa silage & $8 \mathrm{~kg}$ \\
Alfalfa hay & $1 \mathrm{~kg}$ \\
Wheat straw & $0.5 \mathrm{~kg}$ \\
Corn cob mix silage & $1 \mathrm{~kg}$ \\
Rapeseed meal & $1.2 \mathrm{~kg}$ \\
Soybean meal & $0.5 \mathrm{~kg}$ \\
Cereal grain mixture & $6.5 \mathrm{~kg}$ \\
\hline
\end{tabular}

Table 3: Nutritional value of the total mixed ratio

\begin{tabular}{lcccc}
\hline \multirow{2}{*}{ Item } & \multicolumn{2}{c}{ 3 weeks before calving } & \multicolumn{2}{c}{$\mathbf{1}^{\text {st }}$ stage of the lactation } \\
\cline { 2 - 5 } & Original dry matter & $\begin{array}{c}\text { Absolute dry } \\
\text { matter }\end{array}$ & $\begin{array}{c}\text { Original dry } \\
\text { matter }\end{array}$ & $\begin{array}{c}\text { Absolute dry } \\
\text { matter }\end{array}$ \\
\hline Dry matter \% & 46.44 & 100.00 & 47.41 & 100.00 \\
Crude protein \% & 6.32 & 13.61 & 7.76 & 16.37 \\
Fat \% & 1.63 & 3.51 & 1.70 & 3.59 \\
ADF \% & 10.63 & 22.89 & 9.38 & 19.78 \\
NDF \% & 17.91 & 38.57 & 15.40 & 32.48 \\
Starch \% & 9.96 & 21.45 & 13.85 & 29.21 \\
ASH \% & 3.11 & 6.70 & 3.15 & 6.64 \\
Nitrogen free extract \% & 17.47 & 37.62 & 19.40 & 40.92 \\
Calcium \% & 0.245 & 0.528 & 0.485 & 1.023 \\
Magnesium \% & 0.202 & 0.435 & 0.157 & 0.331 \\
Sodium \% & 0.040 & 0.086 & 0.073 & 0.154 \\
Potasium \% & 0.528 & 1.137 & 0.573 & 1.209 \\
Phosphorus \% & 0.163 & 0.351 & 0.114 & 0.240 \\
\hline
\end{tabular}

Note: ADF - acid detergent fibre, NDF - neutral detergent fibre 


\subsection{Laboratory analyses}

Lipid peroxidation product concentrations (MDA levels) in the serum were measured as thiobbarbituric acid reactive substances (TBARS) according to the spectrophotometric method described by Costa et al. [9] with slight modifications. A $400 \mu \mathrm{l}$ serum sample was mixed with $4 \mathrm{ml}$ of a solution containing equal volumes of $15 \%$ trichloroacetic acid, $0.38 \%$ thiobarbituric acid and $0.25 \mathrm{~N}$-hydrochloric acid. In addition, $40 \mu \mathrm{l}$ of $0.2 \%$ butylated hydroxytoluene was used to prevent lipid peroxidation during heating. The reaction mixture was vortexed and then heated in a boiling water bath for 30 minutes. After cooling in ice water for 10 minutes, the reaction mixture was centrifuged at 3000 rpm for 15 minutes. The same procedure was repeated for MDA standards and a blank test (distilled water). MDA standards were prepared by acid hydrolysis of 1,1,3,3-tetramethoxypropane (malondialdehyde-bis [dimethyl acetal]) and were diluted in the range of 0 to $2 \mathrm{nmol} / \mathrm{ml}$. The absorbance of the supernatant was determined at $535 \mathrm{~nm}$ against a blank test. TBARS concentration was read from a calibration curve prepared according to MDA standards. TBARS values in the serum were expressed in $\mathrm{nmol} / \mathrm{ml}$.

\subsection{Statistical analysis}

We used the GraphPad program (t-test) for statistical evaluation of individual parameters in the first and second monitored groups. We compared the levels of oxidative stress, cholesterol, triglycerides and albumin in the monitored groups. We also used the GraphPad program (linear regression) to statistically evaluate the dependence of triglyceride, cholesterol and albumin levels on oxidative stress.

\section{[3] RESULTS AND DISCUSSION}

We compared the obtained blood parameters with each other, within two monitored groups (3 weeks before calving and the first stage of lactation). We compared oxidative stress, triglycerides, cholesterol and albumin. As reference values for oxidative stress are not set, we can only assess the measured values between the monitored groups. Triglyceride values were above the range of reference values in both groups. Cholesterol and albumin values were within the reference values in both monitored groups (Tables 4 and 5).

Table 4: Oxidative stress and biochemical parameters (3 weeks before calving)

\begin{tabular}{cccccccccc}
\hline Parameter & $\begin{array}{c}\text { Reference } \\
\text { value }\end{array}$ & $\mathbf{1 .}$ & $\mathbf{2 .}$ & $\mathbf{3 .}$ & $\mathbf{4 .}$ & $\mathbf{5 .}$ & $\mathbf{6 .}$ & Mean & STD \\
\hline $\begin{array}{c}\text { Cholesterol } \\
(\text { mmol/l) }\end{array}$ & $1.2-3.3$ & 2.56 & 2.46 & 3.17 & 2.66 & 3.08 & 2.79 & 2.79 & 0.29 \\
$\begin{array}{c}\text { Triglycerides } \\
\text { (mmol/l) }\end{array}$ & $0.17-0.8$ & 1.10 & 1.16 & 1.32 & 1.02 & 1.11 & 1.19 & 1.15 & 0.1 \\
$\begin{array}{c}\text { Albumin } \\
(\text { mmol/l) }\end{array}$ & $27.5-39.4$ & 30.34 & 27.72 & 36.04 & 32.13 & 32.62 & 31.29 & 31.69 & 2.75 \\
$\begin{array}{c}\text { Oxidative } \\
\text { stress }\end{array}$ & & 1.29 & 0.98 & 0.92 & 0.74 & 0.68 & 0.96 & 0.93 & 0.21 \\
\hline
\end{tabular}

Only comparisons of albumin levels and oxidative stress in the monitored groups are statistically significant. Oxidative stress was higher in the cows in the first study group than in the second study group. Albumin levels were lower in the first study group than in the second study group. However, higher OS levels can also be caused by a negative energy balance. According to Lohrke et al. [10] and Bernabucci et al. [11], a negative energy balance triggers catabolic pathways that increase the production of reactive oxygen metabolites at the cellular level.

According to Nordberg and Arner [12], if ROS are formed in excessive amounts or faster than can be removed by antioxidant mechanisms, they can lead to oxidative stress. In this study, we have found that oxidative stress was different and statistically significant in both groups $(\mathrm{p}<0.05)$. The observed parameters in both groups were statistically significant only for albumin ( $\mathrm{p}<0.05$ ). Cholesterol and triglycerides did not show statistical significance between groups ( $p>0.05$ ). When comparing the dependence between oxidative stress and concentration between individual parameters, we found that in the second group of dairy cows with increasing triglyceride concentration, the value of oxidative stress decreased $(\mathrm{p}<0.05)$. For other parameters, statistical significance was not confirmed in either group of dairy cows ( $\mathrm{p}>$ $0.05)$. 
Table 5: Oxidative stress and biochemical parameters $\left(1^{\text {st }}\right.$ stage of the lactation)

\begin{tabular}{cccccccccc}
\hline Parameter & $\begin{array}{c}\text { Reference } \\
\text { value }\end{array}$ & $\mathbf{1 .}$ & $\mathbf{2 .}$ & $\mathbf{3 .}$ & $\mathbf{4 .}$ & $\mathbf{5 .}$ & $\mathbf{6 .}$ & Mean & STD \\
\hline $\begin{array}{c}\text { Cholesterol } \\
\text { (mmol/l) }\end{array}$ & $1.2-3.3$ & 3.13 & 3.2 & 2.83 & 3.35 & 2.54 & 3.18 & 3.04 & 0.3 \\
$\begin{array}{c}\text { Triglycerides } \\
(\mathrm{mmol} / \mathrm{l})\end{array}$ & $0.17-0.8$ & 0.94 & 1.06 & 1.11 & 1.17 & 1.02 & 1.07 & 1.06 & 0.08 \\
$\begin{array}{c}\text { Albumin } \\
(\mathrm{mmol} / \mathrm{l})\end{array}$ & $27.5-39.4$ & 32.43 & 35.53 & 35.95 & 36.3 & 38.55 & 36.21 & 35.83 & 1.97 \\
Oxidative stress & & 0.86 & 0.78 & 0.59 & 0.64 & 0.70 & 0.68 & 0.71 & 0.1 \\
\hline
\end{tabular}

According to Trevisan et al. [13], decreased energy in the first weeks after calving leads to increased fat mobilization, which is associated with lipid peroxidation and ROS production. According to Miller et al. [1], increased intake and higher levels of nutritional antioxidants can effectively reduce lipid peroxidation levels. For this reason, it would be beneficial to supplement the nutrients needed for antioxidant defense. However, according to Abuelo et al. [14], excess antioxidants have the potential to increase ROS production and have been associated with an increased likelihood of health disorders, therefore supplementation in balanced and adequate amounts is needed, and further research is needed into the importance and effects of antioxidants in cow nutrition.

We also compared serum albumin concentrations in both groups of cows. According to the results of the t-test, the difference between the monitored groups is statistically significant $(\mathrm{p}<0.05)$. In the first study group, the albumin concentration was lower than in the second study group, which can be explained by the fact that according to Bertoni et al. [15], a peripartum period is characterized by an inflammatory condition that involves a decrease in the production of acute phase negative proteins such as albumin. As the oxidative stress decreased in the second study group, albumin levels increased. According to Kaneko et al. [16], decreased albumin production may be due to a negative energy balance, and albumin production may be hindered by malnutrition or hepatic dysfunction. However, liver parameters were normal. Albumin is a very important circulating antioxidant [17]. And so at a higher OS, its level is lower. Based on this fact, in addition to MDA and TBARS, we could also monitor the concentration of albumin in the blood as an indicator of oxidative stress in cows. However, our correlation between albumin and oxidative stress was not confirmed in our study.

We also evaluated the correlation between triglycerides, cholesterol and oxidative stress. In the first study group, the correlation between OS and triglycerides was not statistically significant ( $p>0.05)$. But in the second study group, triglyceride levels also increased with decreasing oxidative stress. Triglyceride levels and oxidative stress were thus in inverse proportion in the second group (during the first phase of lactation). Our hypothesis was that oxidative stress affects triglyceride levels. According to Stocker [18], rising levels of MDA indicate overproduction of free radicals, which lead to lipid peroxidation and oxidative cell injury, which is associated with the development of hyperlipidemia. Thus, OS causes hyperlipidemia.

However, according to Rui-Li Yang [19], hypertriglyceridemia and hypercholesterolemia were associated with oxidative modification of LDL, leading to excessive production of lipid peroxidation products, which may increase oxidative stress at higher lipid levels and in hyperlipidemic individuals. Thus, hyperlipidemia led to OS. Thus, according to these studies, both oxidative stress acts on lipid levels and lipid levels act on oxidative stress. Thus, we can say that the level of OS is related to the level of triglycerides in the blood serum. The study of Katsuki et al. [20], also dealt with this but in humans.

\section{[4] CONCLUSION}

In all studies dealing with oxidative stress in cows, its negative effect on cow health is mentioned. We have mentioned this fact several times in our work, so it is important to further research and study of oxidative stress and individual effects on oxidative stress, the effect of feed ration on oxidative stress and also research on how oxidative stress affects fat metabolism in cows. After a thorough examination of all aspects, it is necessary to implement the information obtained in practice in order to minimize oxidative stress and thus improve the life of dairy cows. It is necessary to establish reference points for oxidative stress, which could help in the development of nutritional strategies for the antioxidant defense of cows.

\section{[5] ACKNOWLEDGEMENT}

This work was supported by the Slovak projects VEGA no. 1-0529-19 and KEGA no. 006UVLF-4-2020.

\section{[6] REFERENCES}

[1] Miller, J. K., Brzezinska-Slebodzinska, E., Madsen, F. C. "Oxidative stress, antioxidants and animal function", Journal of Dairy Science. vol. 76, no. 9, pp. 2812- 2823, 1997. 
[2] Čaprnda, M. Oxidačný stres a ateroskleróza, (Univerzita Komenského), Bratislava, p. 87, 2014.

[3] Lykkesfeldt, J., Svendsen, O. "Oxidants and antioxidants in disease: oxidative stress in farm animals", The Veterinary Journal. vol. 173, no. 3, pp. 502-511, 2007.

[4] Förstermann, U. "Nitric oxide and oxidative stress in vascular disease", Pflugers archiv-European journal of physiology. vol. 459, no. 6, pp. 923-939, 2010.

[5] Sugino, N. "Roles of reactive oxygen species in the corpus luteum", Animal Science Journal. vol. 77, no. 6, pp. 556-565. 2006.

[6] Georgieva, N., V. "Oxidative stress as a factor of disrupted ecological oxidative balance in biological systems", Bulgarian Journal of Veterinary Medicine. vol. 8, no. 1, pp. 1-11., 2005.

[7] Janero, D., R. "Malondialdehyde and thiobarbituric acid-reactivity as diagnostic indices of lipid peroxidation and peroxidative tissue injury", Free Radical Biology and Medicine. vol. 9, no. 6, pp. 515-540, 1990.

[8] Council Directive 2010/63/EU of 22 September 2010 on the Protection of Animals Used for Scientific Purposes.

[9] Costa, C. M., SantoS, R. C. C., Lima, E. S. "A simple automated procedure for thiol measurement in human serum samples", Jornal brasileiro de patologia e medicina laboratorial. vol. 42 no. 5, pp. 345-350, 2006.

[10] Lohrke, B., Vierguth, T., Kanitz, W., Göllnitz, K., Becker, F., Hurtienne, A., Schweigert F. "High milk yield in dairy cows associated with oxidant stress", Journal of Veterinary Research. vo. 8, pp. 70-78, 2004.

[11] Bernabucci, U., Ronchi, B., Lacetera, N., Nardone, A. "Influence of body condition score on the relationship between metabolic status and oxidative stress in periparturient dairy cows", Journal of Dairy Science. vol. 88, no. 6, pp. 2017-2026, 2005.

[12] Nordberg, J., Arnér, E. S. J. "Reactive oxygen species, antioxidants, and the mammalian thioredoxin system", Free Radical Biology and Medicine. vol. 31, no. 11, pp. 1287-1312, 2001.

[13] Trevisan, M., Freudenheim, J., Muti, P., Armstrong, D., Browne, R., Dorn, J. "Correlates of markers of oxidative status in the general population", American Journal of Epidemiology. vol. 154, no. 4, pp. 348-356. 2001.

[14] Abuelo, A., Hernandez, J., Benedito, J. L., Castillo, C. "The importance of the oxidative status of dairy cattle in the periparturient period: revisiting antioxidant supplementation", Journal of animal physiology and animal nutrition. vol. 99, no. 6 pp.1003-1016, 2015.

[15] Bertoni, G. Trevisi E., Han, X., Bionaz, M., "Effects of inflammatory conditions on liver activity in puerperium period and consequences for performance in dairy cows", Journal of Dairy Science. vol. 91, no. 9, pp. 33003310, 2008.

[16] Kaneko, J. J., Harvey, J., Bruss, M. “Clinical Biochemistry of Domestic Animals (5th ed.)”, (Academic Press, San Diego), p. $932,1997$.

[17] Roche, M., Rondeau, P., Singh, N. R., Tarnus, E., Bourdon, E. "The antioxidant properties of serum albumin", Febs Letters. vol. 582, no. 13, pp. 1783-1787, 2008.

[18] Stocker, R., Keaney, J. F. "Role of oxidative modifications in atherosclerosis", Physiological Reviews. vol. 84, no. 4, pp. 1381-1478. 2004.

[19] Yang, R. L., Shi, Y. H., Hao, G., Li, W., Le, G. W. "Increasing Oxidative Stress with Progressive Hyperlipidemia in Human: Relation between Malondialdehyde and Atherogenic Index", Journal of Clinical Biochemistry and Nutrition. 2008. vol. 43, no. 3, pp. 154-158, 2008.

[20] Katsuki, A., Sumida, Y., Urakawa, H., Gabazza, E. C., Murashima, S., Nakatani, K., Yano, Y., Adachi, Y. "Increased oxidative stress is associated with serum levels of triglyceride, insulin resistance, and hyperinsulinemia in japanese metabolically obese, normal-weight men". Diabetes Care. vol. 27, no. 2, pp. 631632. 2004. 